\title{
1st national cross-sectional study on meal/snacks and alcohol habits among community-dwelling elderly in Cameroon
}

\author{
G. Mabiama ${ }^{1,2}$, D. Adiogo 2 , P. Fayemendy ${ }^{1,3}$, P. M. Preux ${ }^{1}$, J.C. Desport ${ }^{1,3}$ and P. Jésus ${ }^{1,3}$ \\ ${ }^{1}$ Institute of Epidemiology and Tropical Neurology, GEIST, Limoges, France, \\ ${ }^{2}$ Microbiology, Immunology-Hematology and Morphologic Sciences Laboratory (LMIHSM), Douala University, \\ Douala, Cameroun and \\ ${ }^{3}$ Health Network of the Nouvelle Aquitaine Regional Health Agency Limousin Nutrition (LINUT), Isle, France
}

Dietary habits among elderly are known in certain African countries ${ }^{(1)}$ but not in Cameroon. The aim of this study was to assess meal/ snacks, alcohol frequencies consumption, socio-demographics, and health variations among community-dwelling elderly ( $>=60$ y.o.) in Cameroon.

Food frequency questionnaire was used for meals/snack frequency, and 24 hour-recall for alcohol consumption. The protocol was approved by the Ethics Committee of the University of Douala (Cameroon), data were collected after consent from the participants or their legal representatives. Statistics were performed at $5 \%$ threshold.

599 people were included, aged $68.9 \pm 7.2$ y with a sex ratio $\mathrm{M} / \mathrm{F}$ of $0.93,33.5 \%$ of the population was urban and $66.5 \%$ rural. The sample was representative of the elderly population of the country (age $68.6 \mathrm{y} ;$ sex ratio $\mathrm{M} / \mathrm{F}: 0.9 ; 33.5 \%$ in urban vs. $66.5 \%$ in rural). The number of meals was $2.0 \pm 0.8 / \mathrm{d}$, higher in urban areas $(2.2 \pm 0.8, \mathrm{p}>0.001)$, among $60-69$-year-olds $(2.1 \pm 0.8, \mathrm{p}=0.004)$, educated $(2.1 \pm 0.8, p>0.001)$, active $(2.1 \pm 0.7, p>0.001)$, those with an income $(2.0 \pm 0.8, p=0.014)$, without pathology $(2.4 \pm 0.7, p>0.001)$, not taking classical medication $(2.2 \pm 0.8, \mathrm{p}>0.001)$. Breakfast was consumed by $65.9 \%$, more often in urban areas $(76.1 \%$, $\mathrm{p}<$ $0.001)$, among 60-69yr. (72.1\%, p <0.001), married $(75.5 \%, \mathrm{p}<0.001)$, educated $(71.1 \%, \mathrm{p}<0.001)$, without pathology $(82.2 \%, \mathrm{p}$ $<0.001)$. Lunch was consumed by $55.1 \%$, more often in urban areas $(63.2 \%, \mathrm{p}=0.005)$, among married $(67.1 \%, \mathrm{p}<0.001)$, educated $(66.1 \%, \mathrm{p}<0.001)$ and those without pathology $(70.3 \%, \mathrm{p}<0.001)$. Dinner was consumed by $78.3 \%$, more often in urban areas $(85.6 \%, \mathrm{p}=0.002)$, those with income $(81.2 \%, \mathrm{p}<0.001)$ and those not taking any classical medication $(88.7 \%, \mathrm{p}<0.001) .29 .7 \%$ took at least one snack during the day more often in urban $(44.3 \%, \mathrm{p}<0.001)$, among $>=80$ y old $(49.1 \%, p=0.004)$, educated $(33.7 \%, \mathrm{p}=0.003)$, those without pathology $(48.5 \%, \mathrm{p}<0.001)$ and those not taking classical medication $(38.2 \%, \mathrm{p}=0.002) . \mathrm{A}$ morning snack was consumed by $17.7 \%$, an afternoon one by $24.5 \%$ a night one by $12.4 \% .7 .3 \%$ consumed alcohol, more often among 60 69 -year-olds $(9.5 \%, \mathrm{p}=0.021)$, men $(10.8 \%, \mathrm{p}=0.002)$, married/free union $(11.2 \%, \mathrm{p}=0.002)$, head of household $(9.6 \%, \mathrm{p}=0.009)$, active $(10.3 \%, \mathrm{p}<0.001)$, with income $(9.1 \%, \mathrm{p}<0.001)$, people without pathology $(14.9 \%, \mathrm{p}=0.003)$, not taking any medication $(12.4 \%, \mathrm{p}=0.002)$.

Weak meals frequency $(2.0 \pm 0.8 / \mathrm{d})$, as noted elsewhere (1), might lead to poor nutritional status. Food habits seem more favourable in urban areas, in educated persons and in absence of a pathology. Alcohol consumption is scarce.

\section{Acknowledgements}

We would like to thank the ALAIR-Limousin Association and Health Network of the Nouvelle Aquitaine Regional Health Agency Limousin Nutrition (LINUT) for their financial support and the following members of the Groupe de Recherche sur le Vieillissement au Cameroon (GRVC) for facilitating and/or contributing to the data collection: Dr (Mrs) Véronique Priscille Nguiamba, Mrs Aurélie Michelle Mimba Mengue, Nadège Mayan Matouki, Edwige Laure Nzié, Cécile Nadège Kingué Ekamé, Didja Wassah, Annie Gaëlle Dekembaye, Brigitte Floriane Ombous, Anne Marie Ngo Manyim Ma Mayada, and Mr François Etotogo, Thierry Roland Njille Ehawa, Samaki Charles Yaya, Maurice Menzo, Lionel Wilfried Mbono Mbono; Dr Julien Magne for statistic guidance, as well as the elderly and their legal representatives.

\section{Reference}

1. Kimokoti RW \& Hamer DH (2008) Nutr Rev 66(11), 611-623 